\title{
SOBRE LA DISCUTIDA NATURALEZA OBJETIVA DE LA RESPONSABILIDAD PATRIMONIAL DE LA ADMINISTRACIÓN
}

\author{
TOMÁS-RAMÓN FERNÁNDEZ \\ Universidad Complutense de Madrid
}

Cómo citar/Citation

Fernández, T.-R. (2021).

Sobre la discutida naturaleza objetiva de la responsabilidad patrimonial de la Administración. Revista de Administración Pública, 216, 169-186. doi: https://doi.org/10.18042/cepc/rap.216.06

\section{Resumen}

El significado originario del sistema de responsabilidad patrimonial de la Administración implantado en 1954 ha sido objeto de una grave deformación en los primeros ańos de este siglo, que es forzoso corregir. Lo ha hecho la Sentencia constitucional de 17 de Octubre de 2018, que el autor analiza.

\section{Palabras Clave}

Responsabilidad objetiva de la Administración. 


\section{Abstract}

The original meaning of the Administration's responsability established in 1954 has suffered a serious deformation, which ist necessary to correct. The constituional Sentence of 17.10.2018 has made it and it's analyzed by the author.

\section{Keywords}

Objetive Administration responsability. 


\section{SUMARIO}

I. INTRODUCCIÓN. II. LA SENTENCIA DE 14 DE JUNIO DE 1991 Y LA CRÍTICA DE F. PANTALEÓN. III. LA RADICAL CONTRADICCIÓN DE LA SENTENCIA DE 14 DE JUNIO DE 1991 CON LA DOCTRINA ENTONCES DOMINANTE. IV. LA CONSTRUCCIÓN DEL MANIQUEO DE LA RESPONSABILIDAD OBJETIVA GLOBAL. V. LA CONSTITUCIONALIZACIÓN DEL SISTEMA LEGAL DE 1954. VI. LA SENTENCIA CONSTITUCIONAL DE 17 DE OCTUBRE DE 2018 Y SUS VOTOS PARTICULARES. VII. UNA ACLARACIÓN FINAL.

\section{INTRODUCCIÓN}

Desde la aparición, ¡hace ya treinta años!, de la desafortunada sentencia de 14 de junio de 1991, que puso fin al tristemente célebre asunto de «los dos aneurismas», la confusión se ha apoderado del tema de la responsabilidad patrimonial de la Administración, una confusión que ha llegado al propio Tribunal Constitucional, cuya sentencia de 17 de octubre de 2018 y los votos particulares que la acompañan han contribuido, contra todo pronóstico, a alimentarla, en el escenario doctrinal, al menos. El debate que tuvo lugar en octubre del año pasado en el marco del seminario organizado por la Revista de Administración Pública con los magistrados de la Sala $3^{a}$ del Tribunal Supremo no ha logrado tampoco disiparla, lo que hace muy de temer que se convierta en crónica ${ }^{1}$.

Antes de que esto ocurra es obligado hacer un esfuerzo para aclarar el gran equívoco que ha contribuido a generarla. Esa es mi intención en este momento. Para ello hay que empezar por releer, por leer de nuevo con los ojos de hoy, es decir, con la preocupación que hoy tenemos y, por lo tanto, con el plus de atención que nos exige ahora esa preocupación que no teníamos cuando hicimos su primera lectura, los textos que se han ido acumulando y superponiendo a lo largo

1 Véanse las ponencias de C. Romero Rey, O. Mir Puigpelat, R. Fernández Valverde, L. Medina Alcoz y el informe final de E. Cobreros Mendazona sobre los que giró el debate al que se hace referencia en el texto en el número 213 (2020) de la Revista de Administración Pública, págs. 13 y ss. 
del tiempo haciendo buena la metáfora del palimpsesto que Carlos Romero tuvo el acierto de incorporar al título de su ponencia en el seminario aludido anteriormente $^{2}$.

\section{LA SENTENCIA DE 14 DE JUNIO DE 1991 Y LA CRÍTICA DE F. PANTALEÓN}

Comenzaré el ejercicio por la sentencia de 14 de junio de 1991 y por el implacable análisis crítico que hizo de la misma Fernando Pantaleón ${ }^{3}$.

La relectura de la sentencia ha confirmado la impresión que me produjo la lectura inicial: su extraordinaria simplicidad. Con la calificación constitucional del nuestro como un Estado social y democrático de derecho y el reconocimiento por el art. 43 de la Norma Fundamental del derecho a la salud se consigue - dice la sentencia de la Audiencia Territorial de Madrid de 4 de noviembre de 1985 en uno de los fundamentos jurídicos que hizo suyos el Tribunal Supremo-:

[...] además de la universal responsabilidad de la Administración Pública en los términos fijados por la ley, una generalización de los servicios públicos como potenciales factores de riesgo, que, en la prestación de un servicio concreto a los administrados, pueden provocar una lesión de su persona o bienes patrimoniales. Lesión que, cuando sea efectiva, concreta e individualizada, deberá ser objeto de indemnización, siempre que se pueda establecer un vínculo de causalidad entre el agente público y el resultado lesivo, y no estemos en presencia de un caso de fuerza mayor, única circunstancia exonerante de ese deber general de responsabilidad que incumbe a los servicios públicos.

La sentencia no se plantea ninguna otra cosa. Constata la falta de culpabilidad del cirujano, cuya conducta toma en cuenta solamente «desde la estricta objetividad mecánica de un comportamiento que se inserta, junto con otros eventos, en la causalidad material, a nivel de experiencia, en la producción de un resultado». Esto le basta al Tribunal para decidir, porque — dice— «lo único relevante para la Sala ha de ser la incidencia, a efectos de causalidad, de la intervención quirúrgica llevada a cabo en un Centro de la Seguridad Social». Es esto, la pura causación material del dańo, lo único que importa:

La decisión de atender prioritariamente a la resolución del aneurisma del lado derecho (opción legítima desde las reglas de la lex artis) resultó a posteriori

2 Cfr. C. Romero Rey (2020), La responsabilidad patrimonial de las Administraciones Públicas: un palimpsesto, RAP, 213, pág. 13.

3 Véanse F. Pantaleón (1994), «Los anteojos del civilista: Hacia una revisión del régimen de responsabilidad patrimonial de las Administraciones Públicas", Documentación administrativa, 237-238, págs. 239 y ss., y (1995), Responsabilidad médica y responsabilidad de la Administración, Madrid: Civitas. 
y a nivel de experiencia desacertada, convirtiéndose en una de las concausas relevantes a la hora de valorar, desde una pura perspectiva de la causalidad material de los actos, las consecuencias lesivas de la operación.

Resulta realmente sorprendente esta radical simplificación del problema, porque el juzgador era plenamente consciente de que la paciente llegó al hospital en una "gravísima situación clínica», como subraya, por cierto, a la hora de concretar «el alcance del deber reparador de la Administración titular del servicio público», cuando precisa que deben excluirse los resultados lesivos «propios e inherentes» a esa gravísima situación. Y más sorprendente todavía es que, a pesar de constatar que el jefe de Sección del Servicio de Neurocirugía puso en conocimiento del marido de la paciente, antes de iniciar la operación, el alto riesgo de esta $^{4}$, no se plantee siquiera la influencia que el consentimiento prestado pudiera tener a la hora de imputar a la Administración la responsabilidad por el resultado, supuesto que todos tenemos el deber de hacer frente a las consecuencias de nuestros propios actos.

Nada de eso se tuvo en cuenta, sin embargo, y nada de esto se echó en falta tampoco por quienes analizaron la sentencia. Es verdad, desde luego, que las leyes entonces vigentes (art. 121 de la Ley de Expropiación Forzosa y art. 40 de la Ley de Régimen Jurídico de la Administración del Estado de 1957) no hacían alusión a la inexistencia de un deber jurídico de soportar el daño de acuerdo con la ley, precisión esta que introduciría más tarde el art. 141.1 de la Ley 30/1992, de 26 de noviembre, pero no lo es menos que en la primera explicación que se dio del nuevo sistema E. García de Enterría dejó meridianamente claro que el concepto de lesión en el que se apoyaba el art. 121 de la Ley de Expropiación Forzosa debía entenderse como un perjuicio antijurídico, esto es, como un «perjuicio que el titular del patrimonio considerado no tiene el deber jurídico de soportarlo» ${ }^{5}$. Prescindir de este dato decisivo, como lo hizo la sentencia de 1991, no tiene disculpa, por lo tanto. Tampoco Pantaleón, que escribe su crítica en 1994, vigente ya, por lo tanto, la Ley 30/1992, hizo uso en su análisis del argumento, al que se refirió como si ese deber de soportar el daño solo pudiera ser impuesto por la ley, lo que no es así con toda evidencia ${ }^{6}$.

4 El único que llamó la atención sobre este extremo, a mi juicio capital, fue L. Martín Rebollo en La responsabilidad patrimonial de las Administraciones Públicas en España: estado de la cuestión, balance general y reflexión critica, en el no 237-238 de Documentación Administrativa, enero-junio, 1994, pág. 38. Sin embargo, el abogado del Estado no hizo uso del argumento en el proceso en el que, según indica Martin Rebollo, loc. cit., pág. 39, «se opuso a la demanda por entender que no era posible admitir la existencia de una relación de causalidad entre el daño y el hecho productor del mismo imputable a la Administración».

5 Véase E. García de Enterría (1956), Los principios de la nueva Ley de Expropiación Forzosa, Madrid, pág. 175 (2ª ed., Civitas, 1984), antes en Anuario de Derecho Civil, 1955, págs. 1024 y ss.

6 Véase F. Pantaleón, 1994: 249 y ss. 
Ya desde este momento, por lo tanto, se dio por la sentencia de 1991 y por una parte de la doctrina que siguió la línea crítica del ilustre civilista una versión deformada del ciertamente novedoso régimen legal de la responsabilidad patrimonial de la Administración que introdujo en 1954 la Ley de Expropiación Forzosa y sobre esa versión deformada, según la cual la Administración responde siempre inevitablemente de cualquier perjuicio que una persona pueda sufrir «siempre que se pueda establecer un vínculo de causalidad entre el agente público y el resultado lesivo", cualquiera que sea dicho vínculo ${ }^{7}$, y no sobre la inicial que diera E. García de Enterría y que tenemos buenas razones para considerar interpretación auténtica del art. 121 de la Ley de Expropiación Forzosa de $1954^{8}$ es sobre la que se ha montado curiosamente toda la crítica posterior del sistema introducido por dicho artículo, que la Constitución y las leyes posteriores al mismo han ratificado.

La confusión hoy reinante tiene aquí su origen.

\section{LA RADICAL CONTRADICCIÓN DE LA SENTENCIA DE 14 DE JUNIO DE 1991 CON LA DOCTRINA ENTONCES DOMINANTE}

De la lectura del trabajo de Fernando Pantaleón llama también la atención su afirmación de que las sentencias de la Audiencia Nacional y del Tribunal Supremo que comenta «han aplicado de manera impecable la interpretación absolutamente dominante del régimen legal de responsabilidad de la Administración»?

Esta afirmación es errónea, radicalmente errónea. Lo es porque la tesis que luce en las sentencias en cuestión no se parece en nada a la interpretación del nuevo sistema de responsabilidad que hizo García de Enterría, que en ese momento es, sin duda, la absolutamente dominante, como el propio Pantaleón reconoce en la primera nota a pie de página de su trabajo ${ }^{10}$.

La relectura de aquella primera y autorizada interpretación es también imprescindible ahora. En ella no se afirma en absoluto que el art. 121 de la Ley de Expropiación Forzosa haya establecido un sistema de responsabilidad objetiva global, como se viene afirmando en estos últimos años. Lo que dice es que la ley ha eliminado la consideración de los elementos de ilicitud y culpa para construir la institución de la responsabilidad administrativa, trasladando el centro de gravedad del sistema al concepto de lesión, lo que fuerza a reconstruirlo cuida-

7 Sic en la sentencia de la Audiencia Territorial, que califica la decisión de atender primero al aneurisma del lado derecho como «una de las concausas relevantes a la hora de valorar, desde una pura perspectiva de la causalidad material de los actos, las consecuencias lesivas de la operación». Con una, pues, era suficiente.

8 Como redactor reconocido del anteproyecto de ley.

9 Cfr. Pantaleón, 1994: 244.

10 Ibid: 239. 
dosamente para hacerle capaz de soportar el ingente peso que sobre él se echa ${ }^{11}$. Esa reconstrucción pone el acento en la antijuridicidad del perjuicio sufrido por la víctima, una antijuridicidad que deriva no de la presunta conducta irregular o antijurídica del sujeto que lo produce (criterio subjetivo), sino de la injusticia misma de dicho perjuicio (criterio objetivo), que es, en efecto, antijurídico, injusto, porque el titular del patrimonio considerado no tiene el deber jurídico de soportarlo, aunque el agente que lo ocasione haya obrado él mismo con toda licitud. «La nota de la antijuridicidad se desplaza desde la conducta subjetiva del agente, donde la situaba la doctrina tradicional, al daño objetivo del patrimonio deñado» ${ }^{12}$.

Y para que quede bien claro el alcance de este giro, de este desplazamiento de la antijuridicidad al daño producido se ańade inmediatamente a continuación que "la calificación de un perjuicio en justo o injusto depende de la existencia o no de causas de justificación (civil) en la acción personal del sujeto a quien se impute tal perjuicio» ${ }^{13}$. La lista de estas causas de justificación que se enuncia para ilustrar la idea es, ciertamente, muy corta, y se ha limitado a los supuestos más obvios, lo que deja la explicación en sus inicios, pero no hay que olvidar que se formula simplemente a título de ejemplo ${ }^{14}$.

«El concepto técnico del daño o de lesión, a efectos de responsabilidad civil, requiere, pues — se concluye-, un perjuicio patrimonialmente evaluable, ausencia de causas de justificación (civiles), no en su comisión, sino en su producción, respecto al titular del patrimonio contemplado y, finalmente, la posibilidad de imputación del mismo a tercera persona», puesto que si el perjuicio se imputase al propio titular o a una causa externa e irresistible, no se daría la nota esencial de antijuridicidad; si fuese al propio titular, porque no es concebible que nadie pueda hacerse agravio jurídico a sí mismo, y si se trata de fuerza mayor porque faltando un sujeto no puede trabarse la relación de antijuridicidad ${ }^{15}$. En este último elemento de la imputación se integran ahora, como simples modalidades de la misma, la culpa y el riesgo, pero a su lado existen también otras formas igualmente netas de imputación: la comisión material y perfectamente lícita del daño, la comisión voluntaria y formalmente ilícita, aunque con buena fe subjetiva (ejemplo: arts. 360, 361, 375, 453, etc., del Código Civil), el beneficio patrimonial resultante por el hecho de la lesión misma, aunque no quepa imputar la comisión material del propio hecho dañoso»" ${ }^{16}$.

El problema no se acaba, por lo tanto, como afirmó la sentencia de 14 de junio de 1991, en la causalidad, problema este material, fáctico, sino que se pro-

11 Cfr. García de Enterría, Los principios de la nueva Ley, cit, pág. 174.

12 Ibid.: 175.

13 Ibid.

14 Ibid.: 177

15 Ibid.: 176.

16 Ibid.: 176 y 177. 
longa necesariamente, una vez resuelto, a la imputación, esto es, a la posibilidad de atribución de las consecuencias del daño producido a una Administración pública, problema este estrictamente jurídico.

Esta fue la presentación inicial de las bases de una teoría general de la responsabilidad civil, en cuyo análisis el autor no pretendió profundizar. En su formulación hubo, sin duda, una dosis importante de entusiasmo y también, quizá, una cierta ingenuidad al no advertir que el empleo del adjetivo «objetivo» y del adverbio «objetivamente» podían llegar a ser malentendidos, pero la explicación era, en principio, muy clara y no merecía la deformación de la que ha sido objeto.

\section{LA CONSTRUCCIÓN DEL MANIQUEO DE LA RESPONSABILIDAD OBJETIVA GLOBAL}

La deformación a la que acabo de aludir es sistemática en la tesis doctoral de Oriol Mir Puigpelat, que se apoya en ella para postular la revisión del sistema ${ }^{17}$. Comienza ya en el párrafo primero de la obra en el que afirma en términos dogmáticos que «el sistema de responsabilidad objetiva global instaurado por la Ley de Expropiación Forzosa de 16 de Diciembre de 1954 ha comenzado a tambalearse tras más de cuarenta años de práctica aceptación doctrinal».

No explica por qué hace esta afirmación, ni qué quiere decir con ella. Se limita a bautizar el sistema legal como de responsabilidad objetiva global, dando a entender que se trata de una responsabilidad universal y que la Administración responde siempre, «no sólo cuando el daño derivara del funcionamiento anormal de los servicios públicos, sino también cuando el servicio público hubiera funcionado de un modo perfectamente normal, esto es, al margen de toda ilicitud o culpa", porque es un sistema "completamente ajeno a la idea de culpa» ${ }^{18}$.

A partir de ahí todo sigue por ese cauce. Basta para comprobarlo el simple repaso del índice del libro y, en concreto, del apdo. 3 del capítulo cuarto del mismo, cuyo título es definitivamente expresivo en este sentido: "Por qué no puede seguir sosteniéndose la responsabilidad objetiva global de la Administración». De los once subepígrafes en los que se desdobla este apdo. 3, nueve tienen como protagonista a esa «responsabilidad objetiva global», que es el maniqueo construido ad hoc para sustituir el diseño original del sistema.

El éxito de la crítica de este así planteada estaba garantizado de antemano. Nadie podría negar - y yo, por supuesto, tampoco - que la responsabilidad objetiva global de la Administración no existe en los países de nuestro entorno, ni que el criterio del riesgo especial no justifica una responsabilidad objetiva global, ni que tampoco el criterio del beneficio puede justificar esa responsabilidad obje-

17 Véase O. Mir Puigpelat (2002), La responsabilidad patrimonial de la Administración. Hacia un nuevo sistema, Civitas.

18

Ibid.: 42. 
tiva global, ni que el principio de igualdad y el principio de garantía patrimonial de los administrados tampoco pueden hacerlo. Nadie puede decir tampoco que el art. 106.2 de la Constitución imponga la responsabilidad objetiva global de la Administración española, que, desde luego, sería un subsidio para las compañías aseguradoras privadas. Todos, sin duda, estamos de acuerdo en que la responsabilidad objetiva global de la Administración es insostenible económicamente y también en que una responsabilidad de este tipo no satisface adecuadamente la función de control que corresponde a la responsabilidad civil de las Administraciones públicas.

Lo que ocurre es que el sistema de responsabilidad patrimonial de la Administración construido por el art. 121 de la Ley de Expropiación Forzosa, que elevó a nivel constitucional el art. 106.2 de la Norma Fundamental en vigor, no es, como ya dije, un sistema de responsabilidad objetiva global, sino algo bastante más sutil, en lo que, curiosamente, la doctrina, con algunas notables excepciones a la que en su momento aludiré, no ha querido esforzarse en profundizar.

Antes de seguir adelante me parece imprescindible concretar la referencia que acabo de hacer a la constitucionalización del sistema.

\section{LA CONSTITUCIONALIZACIÓN DEL SISTEMA LEGAL DE 1954}

Para llevar adelante su tesis, es decir, para dar vía libre a una reconstrucción general del sistema de responsabilidad patrimonial de la Administración en el que la regla general sea la responsabilidad por el funcionamiento anormal de los servicios públicos y la responsabilidad objetiva se limite a supuestos excepcionales y típicos, análogos a los previstos en el Derecho Civil, Mir Puigpelat necesitaba desactivar el art. 106.2 de la Constitución, es decir, negar que dicho precepto haya constitucionalizado el sistema implantado por el art. 121 de la Ley de Expropiación Forzosa.

Lo hace, ciertamente, con soltura apoyándose en las dos diferencias que advierte en el precepto constitucional con respecto al texto de la Ley de Expropiación ${ }^{19}$. La primera se refiere, claro está, a la supresión de los adjetivos «normal o anormal» que en el texto legal calificaban el funcionamiento de los servicios públicos; la segunda alude a la expresión "en los términos establecidos por la Ley» que el art. 106.2 de la Norma Fundamental añade al texto legal en cuestión.

En ambos casos, por lo tanto, la interpretación de Mir Puigpelat se reduce a un puro literalismo que carece de todo apoyo en el contexto, los antecedentes históricos y legislativos y los demás criterios que ordena tener en cuenta el art. 3.1 del Código Civil. Prescinde, pues, absolutamente de los datos que estos podían ofrecer y los sustituye con notorio desenfado por sus propios deseos de que el art. 106.2 de la Constitución termine diciendo lo que a él le interesa que diga.

19 Ibid.: 215 y ss. 
El art. 106.2 llegó a la Constitución, cuyo anteproyecto no hacía referencia alguna a la responsabilidad patrimonial de la Administración, gracias a una enmienda presentada por el grupo parlamentario de la Unión de Centro Democrático, la número 779 concretamente, que no fue objeto de ninguna manifestación en contra, por lo que sin debate alguno se convirtió en el apdo. 2 del art. 10 ¿ Se puede deducir de esto, que es lo único que hay, que el constituyente suprimió la referencia al carácter normal o anormal del funcionamiento de los servicios públicos porque pretendía rectificar sustancialmente el sistema establecido por el legislador un cuarto de siglo antes y aceptado pacífica y unánimemente hasta ese momento por toda la comunidad jurídica? A mí me parece un atrevimiento y una ligereza afirmar tal cosa.

Por lo demás, el hecho de que el art. 106.2 de la Constitución no incluya las palabras normal o anormal no significa en absoluto que quiera excluir la primera para entronizar exclusivamente la segunda. La supresión de ambos adjetivos no cambia absolutamente nada el sentido de la proposición porque el sustantivo funcionamiento incluye, como es notorio, si no se dice nada en contra, sus dos posibles formas de manifestarse.

De la inclusión de la expresión "en los términos establecidos por la Ley» tampoco puede deducirse sin más la remisión en blanco por el constituyente de la regulación de la responsabilidad patrimonial de la Administración al legislador futuro para que este haga con ella lo que bien le plazca en cada momento, incluida la posibilidad de rectificar de inmediato al día siguiente de la entrada en vigor de la Constitución el statu quo ante.

No habiendo, como no hay, ningún dato que apoye esa voluntad rectificadora, suponer esta constituye un manifiesto abuso, tanto más cuanto que la referencia a los términos establecidos por la ley tiene también una explicación muy simple. Es el constituyente el que habla y no tiene más remedio que remitirse al desarrollo ulterior por el legislador del precepto que establece, dada la economía que es propia del lenguaje constitucional. Remisión sí, porque es imprescindible, pero remisión en blanco no, porque nada hay que permita suponer que el constituyente quiso rectificar al legislador anterior y a la cultura jurídica por este generada a lo largo de veinticuatro años.

Lo que hay que entender es, más bien, lo contrario, como en su día destacó Jesús Leguina, es decir, que al tomar esa decisión fundamental, «el Legislador constituyente tuvo en cuenta el régimen de la responsabilidad implantado un cuarto de siglo antes y ya entonces plenamente consolidado» ${ }^{20}$, al que colocó en el más alto nivel normativo.

Puede, quizá, decirse, como hace Leguina, a quien Oriol Mir reconoce, como es obligado, autoridad en la materia, que la cláusula general del art. 106.2 de la Constitución «adolece de alguna aparente ambigüedad al no hacer explíci-

20 Véase J. Leguina, "Sobre el carácter objetivo de la responsabilidad de la Administración», Revista Española de Derecho Administrativo, 136, págs. 669 y ss. 
tos los diferentes ámbitos y modos de actuación administrativa a los que serían respectivamente aplicables los criterios de imputación de daños que en cada caso sean jurídicamente idóneos» y que esa potencial ambigüedad ha propiciado el deslizamiento hacia posiciones de pretendida indiferencia entre ambos modos del actuar administrativo, el normal y el anormal, a la hora de imputar el daño sufrido por la víctima a la Administración, lo que ha llevado a la jurisprudencia «a subvertir literalmente el sistema convirtiendo su naturaleza objetiva en un puro régimen de causalidad material en el que el único elemento relevante de imputación sería el nexo causal entre acción administrativa y daño resultante sin atención alguna a cualquier criterio legal de imputación» ${ }^{21}$.

Pero lo que no puede afirmarse en absoluto es que el precepto constitucional haya dejado enteramente abierto el tema renegando por lo tanto del sistema de responsabilidad con el que el constituyente se encontró en 1978, una responsabilidad que «hay que calificar como objetiva, al venir dada no tanto por una conducta culpable que hay que sancionar sino más bien por un quebranto patrimonial que hay que reparar» por decirlo con las palabras de la sentencia de 4 de marzo de 1983, que Leguina recuerda ${ }^{22}$.

Si se quieren corregir los excesos y las desviaciones, lo que procede es esforzarse en perfeccionar el dibujo que el art. 106.2 de la Constitución contiene, para lo cual contamos con los materiales que proporciona una larga experiencia, no empeñarse en hacer decir a dicho precepto lo que no dijo para regresar al punto de partida y empezar otra vez desde cero.

\section{LA SENTENCIA CONSTITUCIONAL DE 17 DE OCTUBRE DE 2018 Y SUS VOTOS PARTICULARES}

Así estaban las cosas en el momento en el que hizo aparición en escena la sentencia constitucional de 17 de octubre de 2018, que hubiera podido poner punto final a este ya antiguo y, desde luego, enojoso equívoco que nos tiene tan confundidos, si no hubiese sido por la disidencia formalmente expresada por tres magistrados del Alto Tribunal que ha contribuido inopinadamente a prolongarlo ${ }^{23}$.

Del objeto del proceso y de su tratamiento no voy a decir nada aquí porque lo ignoro todo acerca de la modificación de la disposición adicional novena del texto refundido de la Ley de Tráfico, circulación de vehículos a motor y seguridad vial acordada por la Ley 6/2014, de 7 de abril, y no sé, por lo tanto, las razones que pudieran justificarla, ni los movimientos que la impulsaron. Solo sé lo que

\section{Ibid.: 676. \\ Ibid:: 677 .}

23 En esta línea véase la ponencia de O. Mir Puigpelat (2020), «La garantía constitucional de la responsabilidad por el funcionamiento de la Administración», Revista de Administración Pública, 213, págs. 29 y ss. 
dicen los boletines oficiales y eso realmente no es nada. Antes de la modificación se consideraba responsable al conductor en los accidentes de tráfico ocasionados por el atropello de especies cinegéticas «cuando se le pueda imputar incumplimiento de las normas de circulación"; ahora, en cambio, el texto de la disposición cuestionada considera responsable al conductor del vehículo como norma general, aunque no haya incumplido norma alguna, salvo que el accidente de tráfico sea consecuencia directa de una acción de caza colectiva de una especie de caza mayor llevada a cabo el mismo día o que haya concluido doce horas antes de dicho accidente, en cuyo caso serán responsables los titulares de los aprovechamientos cinegéticos o, en su defecto, los propietarios de los terrenos. ¿’Por qué este cambio? No hay respuesta oficial a esta pregunta quizá porque la que pudiera haber no es exhibible.

La ausencia de toda explicación del cambio introducido ha proyectado en cualquier caso sobre el asunto la sombra ominosa de la arbitrariedad, sobre la que, sin embargo, la sentencia no se ha pronunciado, lógicamente, ya que nadie planteó formalmente el argumento en el curso del proceso. La sombra, sin embargo, está ahí y muy probablemente no ha dejado de tener influencia en el desarrollo y, quizá también, en el propio desenlace de la cuestión plantead ${ }^{24}$.

Porque, en efecto, la sentencia resuelve una cuestión de inconstitucionalidad de la disposición adicional novena de la Ley de Tráfico, versión 2014, por su eventual oposición al art. 106.2 de la Constitución:

[...] en el entendimiento —-según relata la sentencia en su fundamento jurídico $1-$ de que este último precepto constitucional establece un sistema puramente objetivo de responsabilidad patrimonial para las Administraciones Públicas. El órgano judicial estima — continúa relatando la sentencia — que la norma legal cuestionada, al hacer recaer sobre el conductor del vehículo la responsabilidad civil con la sola excepción de los casos en los que la irrupción en la vía pública de la especie cinegética sea consecuencia de una concreta acción de caza mayor, resulta parcialmente inconstitucional, pues en todos aquellos supuestos en los que el titular de la explotación cinegética sea un ente público la responsabilidad patrimonial ha de corresponder, por mandato constitucional, a la Administración implicada con la sola existencia de una conexión causal entre la actividad administrativa realizada y el daño finalmente ocasionado.

La magistrada proponente de la cuestión era, pues, decidida partidaria de la tesis de la responsabilidad objetiva global difundida por Mir Puigpelat, lo que,

24 El argumento de la posible arbitrariedad de la norma enjuiciada aparece en los escritos del abogado del Estado, del fiscal y de la Federación Española de Caza, así como en el propio auto de planteamiento de la cuestión. Pero es formalmente descartado por la sentencia en su fundamento jurídico 1 por entender que esta problemática desborda «el ámbito estricto de la cuestión que se nos plantea, que no va formalmente referido a ese concreto vicio de inconstitucionalidad, sino a la vulneración del artículo 106.2 CE». 
naturalmente, obligaba al tribunal a pronunciarse sobre la interpretación correcta del art. 106.2 de la Constitución.

Realmente no le costó demasiado hacerlo porque, en rigor, había avanzado ya su postura al respecto en una Sentencia anterior, la 141/2014, de 11 de septiembre, que resolvió los recursos de inconstitucionalidad interpuestos contra la Ley 8/2007, de 28 de mayo, de Suelo y contra el texto refundido subsiguiente. Uno de los arts. impugnados era el 11.5 del citado texto refundido, según el cual el incumplimiento por la Administración del deber de resolver en plazo sobre la aprobación de los instrumentos de ordenación o ejecución urbanística «dará lugar a indemnización a los interesados por el importe de los gastos en que hayan incurrido para la presentación de sus solicitudes», salvo en los casos en que tales instrumentos pudieran entenderse aprobados por silencio administrativo.

El motivo de la impugnación de este precepto fue que daba a entender que consagraba la responsabilidad de la Administración en un supuesto «independiente de la existencia de una lesión efectiva en los bienes y derechos de los interesados en una relación causal con el funcionamiento de los servicios públicos», lo que le permitió al tribunal precisar que la interpretación literal de la norma, según la cual la Administración tendría que abonar al particular el importe de los gastos incluso aunque la demora no fuere atribuible al funcionamiento de los servicios públicos (podría ser atribuida a la propia conducta del particular) e independientemente de que se hubiera o no producido una lesión efectiva (podría ocurrir que tuviera lugar una resolución tardía favorable y que no surgiera lesión alguna):

[...] resulta contraria al artículo 106.2 CE que prevé la responsabilidad patrimonial de la Administración sólo cuando el dańo es imputable al funcionamiento de los servicios públicos y cuando el particular sufra una lesión efectiva».

No hacía falta decir más para dejar zanjado el asunto, ya que con eso bastaba para mostrar que cabía una interpretación conforme del precepto impugnado con solo leerlo a la luz de la norma constitucional así entendida, en sintonía, por lo tanto, con la interpretación tradicional de la misma que hasta la sentencia de 14 de junio de 1991 se había mantenido nemine discrepante.

Sobre la base de este precedente la sentencia de 17 de octubre de 2018 no tuvo la más mínima duda al afirmar:

[...] que el tenor literal del artículo 106.2 supone la recepción constitucional del sistema de responsabilidad de la Administración previamente vigente en España, cuyo carácter objetivo venía siendo ampliamente aceptado por la doctrina y la jurisprudencia.

La sentencia explica a continuación la procedencia del precepto, la enmienda presentada por la UCD y recuerda que reproduce parcialmente el texto de las Leyes de Régimen Jurídico de la Administración del Estado y de Expropiación Forzosa, lo que la permite afirmar a modo de consecuencia que: 
[...] así pues, el régimen constitucional de las Administraciones públicas se rige por criterios objetivos, que implican la necesidad, no sólo de examinar la relación de causalidad, sino también la de formular el juicio de imputación del dańo que permita conectar suficientemente el perjuicio producido con la actividad desarrollada por el agente del mismo, en este caso por una Administración pública.

«Esa es, claramente, la línea de interpretación marcada en nuestra propia doctrina», dice, refiriéndose a su sentencia 141/2014, cuyo contenido recuerda, para terminar afirmando que "de este modo", es decir, teniendo en cuenta las explicaciones que acaba de dar:

[...] la remisión del artículo 106.2 CE al desarrollo legislativo no puede, en modo alguno, explicarse como una mera autorización al legislador para que determine el régimen jurídico de la responsabilidad de la Administración; se trata, más bien, de una regla de cierre que permite al legislador concretar la forma en que una responsabilidad puede ser exigida.

Es una lástima que, habiendo dejado tan claras las cosas, tres magistrados hayan disentido de la mayoría del tribunal formulando por escrito dos votos particulares.

Ambos consideran «inasumible» ${ }^{25}$ con toda razón que la Administración deba ser responsable siempre por el mero hecho de estar involucrada en la materialización causal de un daño, pero, como creen que eso viene de una determinada interpretación del art. 106.2 de la Constitución, no encuentran mejor salida que afirmar que el precepto citado dejó abierto el tema de la responsabilidad de la Administración entregándoselo así al legislador ordinario para que establezca el modelo que mejor le parezca.

No hay, sin embargo, en ninguno de los dos votos particulares nuevos datos $\mathrm{y}$, menos aún, nuevos argumentos más allá de los ya considerados con anterioridad, que avalen esta interpretación del art. 106.2 de la Constitución y que justifiquen el rechazo de la tesis que la sentencia de la mayoría hace suya de que dicho precepto «supone la recepción constitucional del sistema de responsabilidad de la Administración previamente vigente en España, cuyo carácter objetivo venía siendo ampliamente aceptado por la doctrina y la jurisprudencia».

La afirmación que el señor Ollero Tassara hace en su voto particular de que «tales planteamientos fueron en realidad paulatinamente matizados por los más prestigiosos maestros de nuestro derecho administrativo" y de que "como consecuencia, se abrió una línea doctrinal hoy claramente mayoritaria defendida por sus numerosos discípulos» es simplemente inexacta. Está tomada, sin duda, $\mathrm{o}$, por lo menos, influida, por la tesis doctoral de O. Mir Puigpelat, que es quien habló de un "cisma doctrinal», producido a raíz de la crítica que Pantaleón hizo

25 Sic. en el voto particular del señor Narváez. 
de la sentencia de 14 de junio de 1991 y quien adscribió a su gusto a los distintos autores a cada uno de los dos sectores resultantes de la escisión ${ }^{26}$, pero no se corresponde en absoluto con la realidad, como es fácil comprobar con la mera consulta de los manuales de mayor difusión, que son hoy los de J. R. Parada Vázquez, J. A. Santamaría Pastor y G. Fernández Farreres, que siguen instalados en la interpretación tradicional, esto es, en la ofrecida por E. García de Enterría al comienzo de esta historia ${ }^{27}$.

No puedo compartir tampoco la objeción formulada a la sentencia de la mayoría por el señor Narváez en el voto particular que suscribió también el señor Montoya Melgar, porque, a mi juicio, la sentencia sí ha explicado en qué consiste la objetividad del sistema implantado en 1954 y recibido por la Constitución. Es verdad que no ha dicho expresamente que la calificación como objetivo de dicho sistema se debe a que ha situado el foco en la lesión sufrida por la víctima, no en el comportamiento del agente causante del daño, pero esto es algo que realmente estaba implícito en la afirmación de que el art. 106.2 de la Constitución «supone la recepción constitucional del sistema de responsabilidad de la Administración vigente en España, cuyo carácter objetivo venía siendo ampliamente aceptado por la doctrina y la jurisprudencia». Hay, pues, en la sentencia una incorporación por remisión de las explicaciones entonces al uso de ese carácter objetivo y del propio funcionamiento del sistema.

Lo que ocurre es que los magistrados disidentes han olvidado o dejado de lado, tanto me da, esas explicaciones y tienen instalada en su lugar la visión deformada del sistema que Mir Puigpelat se ocupó de difundir. Y así, desde luego, no hay manera de entenderse a pesar de estar de acuerdo en lo fundamental, a saber que nada permite sostener y, menos aún, el art. 106.2 de la Constitución, «que el Constituyente haya deseado que toda Administración pública y, con ello, todos los miembros de la comunidad social (llamados a sufragar su parte alícuota del importe indemnizatorio) estén rígidamente obligados a resarcir cualesquiera perjuicios que puedan materializarse con ocasión del desenvolvimiento de una actividad pública».

Vuelvan los señores magistrados a la explicación originaria del carácter objetivo del sistema establecido en 1954 y olviden la interpretación deformada de la responsabilidad objetiva global, que es eso, una deformación producida por una jurisprudencia hace tiempo abandonada que una teorización posterior ha contribuido inoportunamente a difundir, y así, liberados todos del enojoso equívoco en el que estamos envueltos, podremos de consuno dedicarnos a trabajar en lo que, ciertamente, adolece de falta de estudio a pesar de ser el centro

26 Cfr. O. Mir Puigpelat, (2002: 31 y ss.).

27 Véase J. R. Parada (2012), Derecho Administrativo I, Parte General, Madrid: M. Pons, 19a ed., págs. 566 y ss.; J. A. Santamaría Pastor (2018), Principios de Derecho Administrativo General, II, Madrid: Iustel, $5^{a}$ ed., págs. 430 y ss.; G. Fernández Farres (2018), Sistema de Derecho Administrativo, II, Cizur Menor: Thomson-Reuters, 4a ed., págs. 450 y ss. 
del sistema: cuándo y por qué tenemos el deber jurídico de soportar los daños procedentes de la actividad de las Administraciones públicas.

\section{UNA ÚLTIMA ACLARACIÓN}

Antes de abordar ese estudio me parece necesario aclarar que la vuelta a los orígenes que propongo no pretende en absoluto reivindicar una supuesta superioridad, en razón de su carácter objetivo, del sistema de responsabilidad implantado por el legislador de 1954 y constitucionalizado en 1978 sobre el tradicional.

Más de medio siglo de jurisprudencia pone de manifiesto, como es lógico por otra parte, que la mayoría de los casos en que se reconoce el derecho de la víctima a ser indemnizado por los daños sufridos por ella a consecuencia de la actividad de la Administración (o de la falta de la misma) lo son de funcionamiento anormal, irregular, de esta. Aquellos en los que se reconoce también la responsabilidad de la Administración sin que haya mediado un comportamiento incorrecto de sus agentes son, obviamente, una minoría, como es lógico igualmente. Lo mismo ocurre en otros sistemas que, aunque basados en la culpa, admiten también la responsabilidad de la Administración en algunos casos en los que esta falta, bien por determinación expresa del legislador, bien en virtud de decisiones singulares del juez administrativo, como es el caso del derecho francés. Desde una perspectiva general el cuadro es, grosso modo, muy semejante, como es fácil comprobar.

Pues bien, si todo es tan parecido finalmente, ¿a qué viene entonces tanta discusión? ¿Qué es lo que realmente añade la calificación de nuestro sistema como de responsabilidad objetiva? ¿Qué ventajas se desprenden, si alguna, de ese desplazamiento del centro de gravedad del sistema desde la idea de la culpa a la de lesión, que es en lo que consiste su discutida objetividad?

La respuesta a estas preguntas es muy sencilla en lo que concierne al funcionamiento anormal de los servicios públicos: ese desplazamiento conlleva también el de la carga de la prueba. La víctima no tiene ya que probar que el agente de la Administración actuó irregularmente, porque el punto de partida del sistema es la garantía de la indemnidad de su patrimonio. Será, pues, la Administración quien deba probar, si quiere eludir su responsabilidad, que el servicio público funcionó correctamente.

Los casos de responsabilidad sin falta son, aquí y fuera de aquí, pocos, como es natural, ya que cuando se actúa de forma regular y correcta no se produce normalmente daño alguno. Son también muy heterogéneos, como destaca con acierto Jacques Moreau en su pequeño gran libro sobre la responsabilidad administrativa ${ }^{28}$, por lo que no es fácil encontrar para todos ellos un denominador común. El único posible es de carácter negativo, la inexistencia en todos ellos

28 Véase J. Moreau (1995), La responsabilité administrative, Paris: PUF, 2a ed., págs. 87 y ss. 
de ese deber jurídico de soportar el daño, bien porque no hay ley alguna que lo imponga ${ }^{29}$, bien porque se ha aceptado de antemano el riesgo inherente al servicio público del que el daño sufrido es resultado ${ }^{30}$, bien porque el perjuicio no ha rebasado el nivel que socialmente se acepta como una consecuencia inevitable de la vida colectiva ${ }^{31}$. El análisis puntual de la jurisprudencia es aquí imprescindible, pero debe dejarse ahora para otra ocasión.

29 El art. 54 de la Ley 42/2007, de 13 de diciembre, del Patrimonio Natural y de la Biodiversidad, en la redacción dada al mismo por la Ley 33/2015, de 21 de septiembre, ofrece un claro ejemplo de imposición del deber de soportar los dańos cuando en su apdo. 6 dice: «Sin perjuicio de los pagos compensatorios que en su caso pudieran establecerse por razones de conservación, con carácter general, las Administraciones Públicas no son responsables de los daños ocasionados por las especies de fauna silvestre, excepto en los supuestos establecidos en la normativa sectorial específica». Véase, no obstante, la inteligente interpretación que hace la sentencia de 11 de febrero de 2020 (ponente, Fernández Valverde).

30 Participando en una manifestación violenta que no había sido autorizada (sentencia de 31 de enero de 2003) o ejerciendo una profesión de acusado riesgo (sentencia de 10 de abril de 2000 en el caso de un piloto del Ejército del Aire; sentencia de 29 de enero de 2004, en el caso de una médico nuclear; sentencia de 18 de abril de 2007, relativa a un bombero; sentencia de 20 de febrero de 2003, policía nacional, etc.).

31 O porque el riesgo inherente a la utilización del servicio público «haya rebasado los límites impuestos por los estándares de seguridad exigibles conforme a la conciencia social», como dicen las sentencias de 5 de junio de 1997 y 19 de diciembre de 2014. 
